ppi $201502 Z U 4645$

Esta publicación científica en formato digital es continuidad de la revista impresa ISSN-Versión Impresa 0798-1406 / ISSN-Versión on line 2542-3185Depósito legal pp $197402 Z$ U34

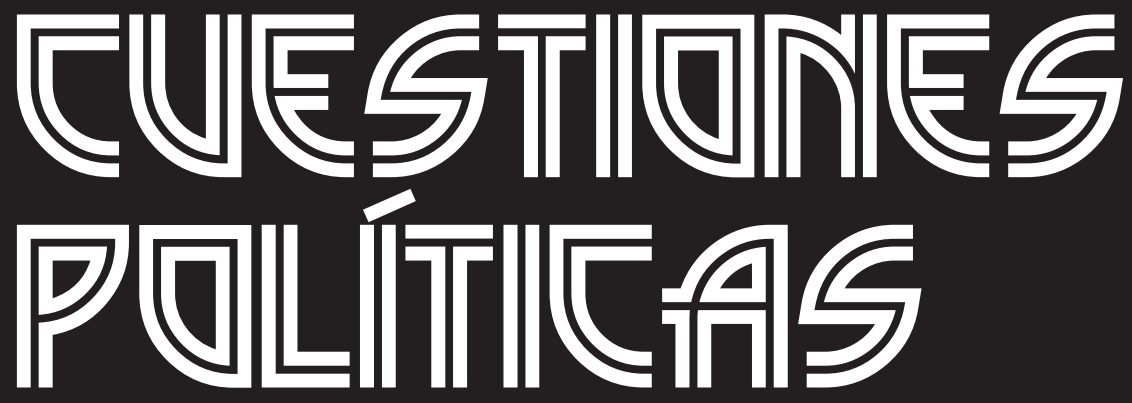

Instituto de Estudios Políticos y Derecho Público "Dr. Humberto J. La Roche" de la Facultad de Ciencias Jurídicas y Políticas de la Universidad del Zulia Maracaibo, Venezuela
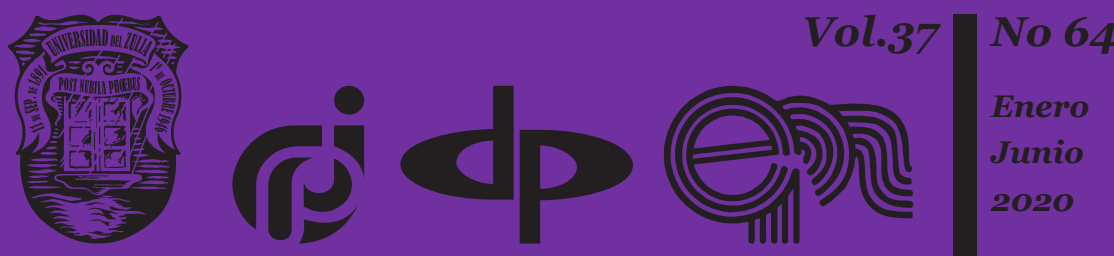


\title{
Legitimidad política y voluntarismo: dos argumentos en favor del consentimiento tácito y la democracia
}

\author{
Adriana L. Vercellone ${ }^{1^{*}}$
}

\section{Resumen}

Este artículo revisa la teoría "voluntarista" y su respuesta al problema de la legitimidad política. Se centra en dos versiones del voluntarismo tácito que se entienden superadores del clásico contractualismo liberal: la teoría de Simmons sobre las abstenciones y las omisiones, y el modelo de asociación voluntaria de J. Tussman. El objetivo es evaluar la plausibilidad de ambos argumentos teóricos, a la luz de las críticas contemporáneas más salientes que ha recibido el voluntarismo clásico. En cuanto a lo metodológico, el trabajo tiene dos partes bien delimitadas. La primera, reconstruye y revisa la consistencia de los argumentos defendidos por las teorías voluntaristas mencionadas, a partir de herramientas interpretativas concretas, como el análisis lógico o la reconstrucción racional. La segunda parte, contrasta dichos argumentos con la práctica política democrática, para evaluar la necesidad de precondiciones y libertades que garanticen un contexto de decisión apto para las manifestaciones de voluntad. Las conclusiones del trabajo sugieren que tanto la propuesta de Simmons como la de Tussman ofrecen una respuesta plausible al problema de la legitimidad política en la medida que sean evaluadas en esquemas de instituciones democráticas que garanticen mecanismos de deliberación y participación.

Palabras clave: legitimidad política; voluntarismo tácito; consentimiento político; abstenciones y silencio en democracia; Simmons y Tussman.

Abogada, Magister en Derecho y Argumentación y Doctora en Derecho por la Universidad Nacional de Córdoba (UNC), Argentina. Profesora en la Facultad de Derecho (UNC). Becaria Postdoctoral CONICET, Argentina. Investigadora en Programa de Ética y Teoría Política del Centro de Investigaciones Jurídicas y Sociales (UNC). Email: adrivercellone@gmail.com. 


\footnotetext{
Adriana L. Vercellone

Legitimidad política y voluntarismo: dos argumentos en favor del consentimiento tácito y la

\title{
Political legitimacy and voluntarism: two arguments in favor of tacit consent and democracy
}

\begin{abstract}
This article analyzes "voluntarist" theory and its response to political legitimacy issue. It emphasizes on "tacit consent" positions, which have overcome classical liberal contractarianism: Simmons's argument about omissions and silence, and Tussman's voluntary association model. The main objective is to assess those theories, in contrast with the most salient critics than voluntarism has received. As for the methodological, this article has two well delimited parts. The first one, reviews the consistency of arguments defended by the theories above mentioned, using interpretative tools, such as logical analysis and rational reconstruction of arguments. The second one, contrasts those analysis with political democratic practice, in order to evaluate some required conditions and freedoms which may guarantee suitable expressions of will.The article concludes that both arguments, Simmons's and Tussman's are a plausible response to political legitimacy, only as they are analyzed in democratic contexts which satisfy specific deliberation and participation mechanisms.
\end{abstract}

Key words: political legitimacy, tacit voluntarism, political consent, omissions and silence in democracy; Simmons and Tussman.

\section{Introducción}

Una discusión central en la teoría política versa sobre la legitimidad de la autoridad y los derechos que ésta reclama sobre los ciudadanos. Básicamente, interroga sobre las condiciones que deben satisfacer las instituciones públicas para tener justificada su potestad de modificar derechos e imponer deberes a los ciudadanos.

El voluntarismo político (o también llamado teoría del consentimiento o contractualismo) ofrece una de las propuestas más destacadas sobre el tema. Poniendo el acento en la manifestación de voluntad de los ciudadanos como antecedente para la formación y justificación de las decisiones institucionales, resalta la importancia del consentimiento como fundamento de la autoridad. Su atractivo radica en que, cuando las personas prestan su consentimiento, la autoridad y sus decisiones pueden ser asumidas como compromisos comunes y, por ello, son legítimas. 
Pero esta explicación sobre la autoridad ha recibido numerosas críticas, razón por la cual sus argumentos han requerido alguna revisión en la teoría política contemporánea. Así, la versión original del argumento elaborada por John Locke en el siglo XVIII, ha mutado hacia novedosas variantes tácitas o hipotéticas acerca de la voluntad que es necesario evaluar.

Este artículo propone reconstruir las diferentes formas que adopta el argumento voluntarista, con el objetivo de evaluar su plausibilidad frente a los problemas que plantea la legitimidad política. Para ello primero se describe el problema, intentando mostrar sus implicancias prácticas y la línea teórica de respuestas en la que se inserta. Luego, se reconstruyen dos versiones contemporáneas del voluntarismo sumamente novedosas: los argumentos de John Simmons y Joseph Tussman. Ambas discurren sobre la consideración de las omisiones y las abstenciones como expresiones de voluntad individual que pueden legitimar a la autoridad, cuestión que ha significado un verdadero problema para el contractualismo clásico. Finalmente, se enuncian algunas ventajas del argumento voluntarista, destacando su vinculación con la justificación de la autoridad en democracia. Pues, en definitiva, las condiciones que plantean ambos teóricos para legitimar a la autoridad, son sólo posibles en sistemas esencialmente democráticos.

\section{Legitimidad política y voluntarismo}

La legitimidad política interroga acerca de los requisitos que debe satisfacer un Estado para encontrarse moralmente justificado; es decir, las condiciones bajo las cuales puede reclamar derechos sobre los miembros de una comunidad política e imponer coactivamente sus decisiones a los incumplidores. En palabras de Simmons, mostrar que un estado es legítimo requiere mostrar que manifiesta (o ha manifestado) cierto tipo de inobjetables relaciones con aquellos sobre quien tiene control y, por ello, se encuentra justificada su potestad de cargar derechos y deberes sobre los ciudadanos (Simmons, 1999). ${ }^{2}$

Se suele distinguir una pregunta conceptual de una pregunta normativa sobre el tema (Seleme, 2010). La primera, refiere al contenido de la legitimidad; es decir, delimita los derechos que el Estado posee sobre los miembros de una comunidad y su posible correlación con obligaciones ciudadanas. Por ejemplo, interroga si la autoridad estatal tiene potestad de

2 Debe distinguirse la cuestión sobre la legitimidad política de la pregunta por la justificación estatal. Ésta última no se preocupa por su justificación, sino por las ventajas de la autoridad estatal; es decir, por qué la organización estatal es preferible y deseable a cualquier otro esquema en el que no existen instituciones (Simmons, 1999). 
Adriana L. Vercellone

Legitimidad política y voluntarismo: dos argumentos en favor del consentimiento tácito y la

legislar y coaccionar a las personas, y si ésta se correlaciona con un deber general de obediencia a las leyes. En otras palabras, la cuestión conceptual responde qué puede hacer el Estado y qué deberes tienen los ciudadanos para con él. El segundo tema -normativo- cuestiona las condiciones que deben darse para que un estado pueda legítimamente reclamar dichos derechos (Peter, 2010; Seleme, 2010); es decir, porqué tiene esas potestades y reclamos. ${ }^{3}$

Las respuestas normativas sobre la legitimidad verdaderamente monopolizan la discusión teórica. ${ }^{4}$ Una de las más destacadas propuestas en dicha línea, concluye que la legitimidad está dada por las interacciones que mantienen los ciudadanos para con el Estado; aunque no por cualquier interacción, sino más bien por la manifestación de la voluntad individual. Así, el voluntarismo político sostiene que cuando los ciudadanos prestan su consentimiento definen quién es la autoridad, sus límites y obligaciones.

Concretamente, el consentimiento político se distingue de cualquier otra expresión de voluntad por los efectos que tiene sobre las personas. Simmons lo define como aquel: "acto deliberado, voluntario, cuyo propósito es cambiar la estructura de derechos de las partes involucradas y generar obligaciones en quienes consienten" (Simmons, 1976: 275). 5 Únicamente el consentimiento puede explicar las potestades de la autoridad política y los deberes que recaen sobre los miembros de la comunidad. Y, en definitiva, la justificación de la autoridad está dada por la manifestación de voluntad de aquellas personas sobre quienes se ejerce.

El inicial aporte para desarrollar este argumento se encuentra en el contractualismo de John Locke. ${ }^{6}$ Locke sostiene que en un estado de naturaleza las personas se rigen por leyes naturales -como la no agresión, la apropiación de tierras no poseídas, o la potestad de castigar a quienes realizan un mal- que transfieren al Estado por medio de la celebración de un contrato voluntario. De este modo, el Estado adquiere derechos sobre el territorio y la población que son un correlato de dichas

3 Otros distinguen no dos, sino cuatro interrogantes diferentes pero relacionados: 1) el problema de los límites de la obligación, es decir, ¿cuándo me encuentro obligado a obedecer? 2) el problema de soberanía, es decir, ¿̇a quién debo obedecer? 3) la diferencia entre autoridad legítima y coacción, es decir, ¿existe alguna diferencia entre una autoridad legítima que ejerce coacción, y la mera coacción? 4) el problema de la justificación de las obligaciones políticas, es decir, ¿̇por qué las personas deben obedecer una autoridad legítima? (Pitkin, 1965; 1966).

4 Existen diferentes respuestas a la cuestión conceptual sobre la legitimidad. Sin embargo, pasaré por alto dichas alternativas, asumiendo que la legitimidad implica potestades en favor de la autoridad y un correlativo deber de obediencia por parte de los ciudadanos, para luego poder concentrar el análisis en la cuestión normativa.

5 La teoría política también ha dedicado espacios a distinguir el consentimiento político de las promesas, contratos y otros actos a los que atribuye diferente significado. Véase (Simmons, 1976; 1981).

6 Existen importantes desarrollos contractualistas previos a Locke, por ejemplo, en los escritos de Hugo Grocio y Thomas Hobbes. Sin embargo, la teoría de Locke es probablemente el mejor antecedente del voluntarismo político, dada su clara concepción de libertades naturales y el correlato que establece entre derechos y obligaciones individuales y los derechos y límites de la autoridad. 
potestades naturales individuales e incluyen, entre otras, la posibilidad de protegerse de agresiones externas, tasar la propiedad privada, prohibir conductas o reforzar las leyes en el territorio (Locke, 1969; 2002). El eje central del argumento Lockeano es que: a) sólo el consentimiento da origen a la autoridad, b) el consentimiento es válido cuando se presta sin la mediación de fuerza o violencia, y c) las personas no pueden transferir voluntariamente un derecho mayor que aquel que poseen en su estado de naturaleza (Simmons, 2009).

\section{El voluntarismo frente a una pregunta política central}

Una de las principales críticas esbozadas contra el voluntarismo político sostiene que las personas no hemos conocido tal estado de naturaleza ni explicitado semejante contrato colectivo para dar origen al Estado. En razón de ello, esta teoría no puede explicar las numerosas comunidades actuales, cuya existencia e instituciones nos preceden y raramente son voluntariamente elegidas (Vilajosana, 2008).

Esto significa que, al apelar a las manifestaciones de voluntad, el voluntarismo es apto para revelar las razones que cada quien tiene al vincularse con su autoridad: el consentimiento individual implica una autorización hacia el esquema de normas o instituciones y el compromiso hacia su cumplimiento. Pero no es una teoría apropiada para explicar la posición que ocupan las numerosas personas que no prestan su consentimiento al Estado, sea porque no lo desean, porque no tienen oportunidad de hacerlo o, inclusive, porque eligen autorizar algunas normas y no otras (por ejemplo, quienes no avalan las normas que creen injustas). La conclusión es que, si sólo el consentimiento es fuente de legitimidad, entonces la comunidad política se encontraría dividida entre quienes se vinculan a la autoridad y la justifican, y quienes no lo hacen; entre quienes obedecen las normas y quienes no tienen dicho deber. No es necesario profundizar sobre lo difícil que se torna la vida colectiva en un contexto así.7

El intento por responder a esta crítica da lugar a diferentes versiones del voluntarismo. Estas se distinguen principalmente por su consideración sobre dos cuestiones: las condiciones que debe satisfacer una acción para que constituya una expresión de voluntad plena (intención, conocimiento,

7 Esto deja entrever las dos cuestiones centrales que plantea la legitimidad política: la "generalidad" y la "particularidad" (Seleme, 2010). Algunos creen que cualquier propuesta sobre legitimidad debe explicar, por un lado, el vínculo de generalidad que une al estado con los ciudadanos -es decir, justificar a la autoridad ante todos y cada uno de los miembros de una comunidad política independientemente de sus acciones o creencias individuales-y, por el otro, explicar por qué cada ciudadano se encuentra particularmente vinculado a su estado, y no a cualquier otro. Puede verse que el voluntarismo responde satisfactoriamente a la particularidad, más a no a la generalidad. 
Adriana L. Vercellone

Legitimidad política y voluntarismo: dos argumentos en favor del consentimiento tácito y la

etc.) y la voluntad frente a la cual se compromete quien presta su consentimiento (a la voluntad propia, a la de una mayoría, o a la que resulte elegida producto del uso de una regla de decisión, como la votación o el sorteo). Así, se desarrollan tres líneas voluntaristas, a saber: a) teoría del consentimiento expreso; b) teoría del consentimiento tácito y; c) teoría del consentimiento hipotético (Vilajosana, 2008).

\section{a. Consentimiento expreso}

Se obliga expresamente quien manifiesta su voluntad de forma directa, con noción de que sus actos y/o dichos implican consentir a la autoridad. Para algunos, la principal característica que define al consentimiento político es el pleno conocimiento respecto de lo que alguien se obliga a nivel público. Así, una persona legitima a la autoridad sólo cuando conoce los futuros efectos políticos de su acción, lo cual sucede cuando esta es directa.

Sin embargo, las manifestaciones de voluntad pueden ser vagas o de significado ambiguo. Por ello el contractualismo clásico se ha esforzados en elucidar las condiciones bajo las cuales dichas expresiones tienen valor político. En líneas generales, sostiene que consentir expresamente implica no sólo un acto consiente sino también la intención de obligarse políticamente (conocimiento además de intención). En otras palabras, alguien debe conocer las consecuencias que tendrá la expresión de voluntad para sí y para la comunidad y, además, debe tener el claro objetivo de que eso suceda. El usual ejemplo proviene de Locke, en cuya teoría es central el propósito que guardaban los ciudadanos que celebraron entre sí el contrato social: someterse a las leyes, marcar límites a la autoridad y a las potestades que el pueblo le cede (Locke, 1969).

Es evidente la fuerza con que la crítica antes mencionada golpea a la teoría del consentimiento expreso, ya que difícilmente todos los miembros de una comunidad consientan expresamente la totalidad de los actos y decisiones de la autoridad estatal. No todos se expresan respecto de la autoridad con conocimiento e intención de los efectos políticos que tendrán sus actos. Por lo tanto, no todos se encuentran en similar posición frente al Estado (Vilajosana, 2008).

Un modo de salvar el argumento establece que es obligatorio manifestarse respecto de la autoridad (por ejemplo, en un sistema de elecciones universales y obligatorias, en el que todos cuentan con plena información y libertad de expresión). Pero, en este caso, las personas razonablemente podrían alegar que su consentimiento se ha dado de forma involuntaria (Vilajosana, 2008), ya que son empujadas a consentir sin posibilidad 
de guardar silencio. Por ello, se concluye que además de conocimiento e intención, es necesario que las manifestaciones de voluntad sucedan sin sujeción a imposiciones externas.

\section{b. Consentimiento tácito}

Muchas de las acciones desplegadas por los ciudadanos pueden ser interpretadas como una expresión de voluntad a la autoridad o a sus normas (Vilajosana, 2008). Para John Locke, por ejemplo, la propiedad privada poseída o disfrutada en un espacio físico implica el reconocimiento de las normas del lugar, sea éste el propietario, un turista ocasional, o alguien que hereda sorpresivamente un terreno (Locke, 1969).

La teoría política contemporánea ha refinado este argumento delimitando el tipo de omisiones, gestos y abstenciones que satisfacen los requisitos de intención y conocimiento y que, por lo tanto, sirven como verdaderas manifestaciones de la voluntad. Para demostrarlo Simmons piensa en el siguiente ejemplo: se planea una reunión en una compañía, y quien lidera la propuesta anuncia que la misma se llevará a cabo al día siguiente en el horario X; seguidamente, pregunta a los presentes si alguien tiene objeción alguna. Simmons cree que, dado el contexto, los asistentes pueden prever que su silencio generará la presunción de aceptar el día y horario propuestos para la reunión (Simmons, 1976).

Existe una gran cantidad de situaciones de las que podemos predicar la misma conclusión y, por ello, se dan múltiples omisiones, abstenciones o actos no explícitos que tienen similar efecto político que el consentimiento expreso. Al evaluar a la comunidad política, Pitkin lo asimila con la jura a la bandera o la participación en elecciones democráticas, gestos que no constituyen expresiones de sometimiento ante la autoridad, pero admiten presumirla (Pitkin, 1965).

Para precisar la cuestión, puede establecerse un parangón entre el consentimiento expreso y el tácito. En primer lugar, ambos tienen el mismo efecto para el agente: legitimar a la autoridad y obligarse frente a ella. Pero se diferencian por el tipo de acción involucrada, pues mientras el primero se muestra a través de una acción actual explícita, el tácito es un acto no explícito, un signo del que puede concluirse la voluntad del agente (Simmons, 1976). En segundo lugar, la intención política del agente puede variar en uno y otro caso. Por ejemplo, se suele afirmar que quien jura la bandera asume un compromiso a largo plazo con su Estado, mientras que la residencia temporal de un turista sólo busca protección transitoria en las normas del territorio. Tanto los actos expresos como los tácitos reflejan 


\begin{abstract}
Adriana L. Vercellone
Legitimidad política y voluntarismo: dos argumentos en favor del consentimiento tácito y la 230

democracia
\end{abstract}

el consentimiento a la autoridad, pero no siempre delimitan con claridad las potestades relegadas ni las obligaciones asumidas. En última instancia estas cuestiones podrán concluirse según el contexto y la acción u omisión involucrada -cuestión no exenta de ulteriores problemas hermenéuticos-. No obstante, aun difiriendo sobre la forma e intención de la expresión de voluntad, tanto el consentimiento tácito como el expreso redundan en efectos equivalentes.

En definitiva, los defensores de esta teoría pretenden mostrar que la legitimidad exige una manifestación de voluntad libre, intencionada y con plena información veraz. Pero también, que las manifestaciones tácitas de voluntad sobre la autoridad satisfacen dichas exigencias. El problema de esta variante del voluntarismo está en que muchos actos no explícitos o abstenciones son en realidad motivados por un desacuerdo o un reproche hacia el esquema institucional imperante en una sociedad determinada; inclusive, algunos ciudadanos pueden acusar tener limitadas sus oportunidades y libertad para expresarse. Por ejemplo, cuando las personas no acuerdan con la autoridad, pero guardan silencio porque temen represalias. Verdaderamente es difícil presumir la voluntad plena y libre en esas circunstancias y en otras similares o peores.

Así, la principal objeción que enfrenta el consentimiento tácito tiene que ver con el alto costo que implica disentir. En circunstancias de injusticia o libertades políticas limitadas, el silencio o las omisiones pueden servir de antecedente para imponer por la fuerza decisiones públicas a los no consentidores (Hume, 1907). Y, en definitiva, la única vía posible de disenso es salirse de la comunidad o abandonar el territorio (Vilajosana, 2008).

\title{
c. Consentimiento hipotético (o constructivo)
}

Un argumento superador de las críticas mencionadas afirma que las personas sólo pueden consentir instituciones que no ejercen violencia o injusticias en contra de ellas. La base de esta tesis se halla en algunos de los argumentos de John Rawls, quien afirma que: "Los arreglos institucionales injustos son una clase de extorsión, inclusive de violencia, y el consentimiento prestado a ellos de ningún modo obliga" (Rawls, en Simmons, 1976: 277). ${ }^{8}$

En definitiva, un gobierno legítimo sólo es aquel que puede ser evaluado positivamente desde una perspectiva racional e imparcial. La conclusión

8 Vale destacar que no podemos identificar a Rawls como un voluntarista, dada su defensa de la legitimidad apelando al ideal de justicia por encima de las interacciones humanas voluntarias con el Estado. Véase Rawls (1999; 2012). 
es que encontrándose en una posición de racionalidad ideal, las personas autorizarían instituciones que cumplen ciertos criterios o valores objetivos, como la justicia o la equidad. Así, cuando un Estado satisface dichos criterios, puede presumirse el consentimiento de la comunidad hacia ellos.

El problema de esta teoría es que no parte de una expresión real de la voluntad, sea expresa o tácita, sino que la construye a partir del contexto institucional. Y por ello se le critica hacer depender los deberes y derechos individuales exclusivamente del carácter moral de la institución o de rasgos de la persona que ejerce la autoridad, pero no de la voluntad de los ciudadanos. En definitiva, nadie ha preguntado a las personas si aprueban las instituciones; su respuesta se deduce de una consideración imparcial sobre las instituciones o la autoridad. Como corolario, las instituciones se impondrían de forma involuntaria sobre las personas.

\section{d. Consentimiento de la mayoría y consentimiento individual}

Una última distinción sostiene que las personas pueden obligarse frente a la autoridad que individualmente consienten o frente a aquella que la mayoría de sus conciudadanos consiente. En la primera, interesa lo que el agente desea, pero en la segunda importa lo que la generalidad de su comunidad acepta.

En principio, el consentimiento mayoritario nada dice sobre el modo en que deben participar los ciudadanos, ni los casos en los que el silencio puede tener un significado político. Por lo tanto, es compatible con cualquiera de las expresiones de consentimiento enunciadas (expreso, tácito e hipotético) y con cualquier forma de gobierno (representativa, autoritaria o inclusive una que decide todo por sorteo). Sin embargo, es de particular interés cuando rigen mecanismos democráticos, ya que la participación de la ciudadanía en elecciones supone la aceptación de las reglas de juego democráticas y, luego, la justificación de la autoridad. Al aceptar el esquema de decisión mayoritario, las personas aceptan también cualquier resultado que éste permita alcanzar, aun cuando su propuesta individual no es la vencedora.

Esta versión del voluntarismo puede responder algunas de las críticas mencionadas, pero - al igual que las teorías del consentimiento hipotéticono resuelve el problema de la imposición de sistemas injustos. Alguien podría reprochar una política pública, pero encontrarse obligado a ella porque la mayoría de sus conciudadanos la aprueba. Este problema toma un especial cariz cuando se considera que las personas no tienen oportunidad de elegir quienes forman parte de su comunidad. 
En otras palabras, el voluntarismo también debe explicar por qué el consentimiento de personas con las que alguien no comparte vínculos especiales lo obliga más que la propia voluntad. Si lo que importa es la asunción de responsabilidades por los propios compromisos asumidos ¿por qué las promesas de otros podrían generar obligaciones o responsabilidades? Alguien puede nacer en un contexto social sumamente injusto, pero estar obligado a aceptarlo porque la mayoría lo hace. O imagínese que alguien no celebra ningún contrato con sus vecinos, no desea hacerlo o inclusive duda de su capacidad para decidir, ¿por qué debiera guiarse por lo que otros desean? (Pitkin, 1965).

\section{Dos argumentos en favor del voluntarismo tácito}

Sin dudas que la tesis voluntarista es atractiva, ya que enraíza en uno de los valores políticos humanos fundamentales: la libertad. Al construir las instituciones y la autoridad desde expresiones individuales voluntarias, las personas pueden legitimarlas y reconocerlas como una extensión de las propias decisiones. Sin embargo, como se indicó, enfrenta un problema fundamental: la reducción significativa del cuerpo político de una comunidad cuando no todos prestan su consentimiento a la autoridad. Los intentos argumentativos por escapar de esta crítica devienen en un segundo problema: la imposición de esquemas injustos a las personas.

Una respuesta al primer problema puede hallarse en la propuesta de John Simmons. Simmons especifica las condiciones bajo las cuales el consentimiento tácito tiene similares efectos políticos que el expreso y, por lo tanto, permite presumir la autorización a la autoridad de quienes se mantienen pasivos frente a ella. Así, que muchos no se expresen directamente sobre el Estado, no impide su legitimación. Cabe aclarar que las conclusiones de Simmons son de corte anarquistas -pues admite que no todos los ciudadanos consienten a la autoridad, razón por la cual rara vez los Estados son legítimos-; sin embargo, su tesis constituye un argumento de peso en favor del voluntarismo tácito.

Una segunda propuesta elaborada por Joseph Tussman avanza sobre la elucidación del contenido del consentimiento tácito y la pertenencia a las comunidades políticas. Este teórico combina los clásicos argumentos voluntaristas sobre la libertad y las obligaciones morales, con análisis históricos sobre la comunidad y el acuerdo, para delinear una idea fundamental: que la pertenencia a una comunidad es voluntaria. Esencialmente, para Tusmann la posibilidad de discutir los acuerdos que se encuentran en la base de la comunidad son un indicio de membresía voluntaria a ella. Por ello, nadie puede argüir que es apresado por el Estado, o por las instituciones y decisiones de sus conciudadanos. 


\section{a. Simmons: efectos y condiciones del consentimiento tácito}

Simmons asimila los efectos políticos plenos que tienen los actos explícitos con los tácitos y, por ello, aun cuando no existen manifestaciones expresas de voluntad, el cuerpo político de la comunidad no necesariamente se reduce. Para explicarlo, recurre al ejemplo de Locke sobre el asentamiento voluntario en un territorio y se pregunta: ¿existe alguna diferencia entre los nativos que eligen sentar su propiedad y familia en un territorio, y los turistas ocasionales que lo eligen como destino vacacional? La diferencia está dada por la forma de manifestar la voluntad y el objetivo perseguido con ella: mientras los habitantes desean mantener relaciones a largo plazo con la comunidad e influir en las decisiones estatales, los segundos esperan protección estatal por el período de tiempo que dure su visita en su espacio físico. Sin embargo, el efecto político es siempre el mismo: la residencia es una muestra de consentimiento, que legitima u obliga ante la autoridad (Simmons, 2009).

Así, aunque la extensión temporal o la intención del agente para con la comunidad pueda variar, Simmons remarca que todo consentimiento político - sea tácito o expreso- se orienta a recibir beneficios y obligarse frente a las normas estatales. Y dicho efecto muchas veces pude implicarse, además, en función de las condiciones del contexto en que se manifiesta, como en el caso de los turistas o quienes compran un terreno y allí se asientan. Esto es interesante porque, entonces, el efecto del consentimiento no depende de la forma de manifestación, sino del contexto de quien lo exhibe (Simmons, 2009).

La conclusión es que la falta de consentimiento expreso generalizado no es obstáculo para atribuir a los residentes de un Estado su manifestación tácita respecto de las instituciones. Y, principalmente, que dicha manifestación de voluntad no es más débil que la "expresa" ni posee un contenido menor (Simmons, 2009).

Pero el verdadero aporte de Simmons tiene que ver con la elucidación del tipo de signos que implican consentir tácitamente. Porque, como se señaló, a veces es injusto que cualquier abstención u omisión admita presumir legítimos efectos políticos. Y, por ello, enumera cinco condiciones que el contexto debe satisfacer para que esto suceda a cabalidad:

1. La situación debe hacer presumir con claridad que el consentimiento puede expresarse a través de una omisión o gesto, y el individuo debe ser consciente de ese hecho.

2. Las personas deben conocer y comprender que cuentan con medios $\mathrm{y}$ un tiempo razonable para disentir. 

Adriana L. Vercellone
Legitimidad política y voluntarismo: dos argumentos en favor del consentimiento tácito y la 234 democracia

3. El agente debe conocer también el momento a partir del cual ya no puede expresarse la voluntad, aun cuando sea información divulgada de modo informal.

4. Los medios aceptados para disentir deben ser razonables y fácilmente ejecutables.

5. Las consecuencias de disentir no deben ser perjudiciales o altamente costosas para la persona (Simmons, 1976).

De acuerdo con la primera condición (1), el consentimiento solo puede ser justificado cuando es evidente que es una fuente de obligaciones para las personas. Y, por encima de todo, cuando esta información es cierta y al alcance de los potenciales consentidores. Las personas deben conocer no sólo el efecto de sus omisiones, sino también, que éste es un medio de consentimiento aceptable. Las siguientes cuatro condiciones (2, 3, 4 y 5) se relacionan con la intención como elemento de la voluntad. Sólo cuando disentir no es una posibilidad costosa y puede ser efectuada en un razonable período de tiempo, entonces puede presumirse la intencionalidad de la persona. No es posible señalar una acción como voluntaria, si la persona cree que será sancionado o que es muy alto el costo de disentir con la autoridad.

Lo valioso de la enumeración de Simmons está en mostrar que, cuando se habla de manifestaciones expresas o tácitas de voluntad, los factores volitivos no son más fuertes en una o en otra. Y así, ciertos gestos, abstenciones $\mathrm{u}$ omisiones trasmitidos bajo determinadas condiciones, tienen fuerza suficiente para vincular a las personas con las instituciones. ${ }^{9}$

\section{a.1. Implicar consentimiento vs. signos reales de la voluntad}

Todavía pueden existir algunas dudas o problemas cuando se trata de determinar y presumir la voluntad ajena a partir de abstenciones o gestos. Para contribuir a despejar estas cuestiones, Simmons delinea una última distinción entre: acción u omisión que "es un signo de consentimiento" y aquella que puede "implicar consentimiento". La posibilidad de "implicar consentimiento" incluye situaciones en las que no hay expresión de voluntad alguna, pero normalmente serían consideradas de genuino consentimiento

9 Debe destacarse que Simmons no reconoce que todos los estados sean legítimos porque no todos prestan de hecho su consentimiento. Sin embargo, esta concesión que hace al anarquismo no tiene que ver con las críticas al consentimiento tácito que se intentan despejar, sino con la fuerte intuición de Simmons de que, aun cumpliéndose las cinco condiciones enumeradas, algunas personas pueden tener buenas razones para no consentir. De todos modos, esto no torna irrelevante a la pregunta por la legitimidad política (Simmons, 2009; 1976; 1981; 1999; Wellman y Simmons, 2005). 
por el contexto y el estado del agente. De forma no exhaustiva, Simmons enumera tres casos comunes:

- Cuando el contexto permite concluir que alguien se encontraba en una posición ideal o en un estado mental ideal para consentir, sin que haya expresado su voluntad;

- Cuando un acto previo compromete al agente a prestar su consentimiento; cita como ejemplo a quien defiende con fuerza que las personas racionales deben expresar su voluntad, pero luego no podría negarse a hacerlo si se percibe como un agente racional;

- Cuando una acción obliga moralmente a consentir; y para mostrarlo imagina a quien ingresa a ver un juego de baseball: al ingresar voluntariamente al partido no puede negar las reglas del deporte (Simmons, 1976).

Efectivamente, Simmons cree que las tres constituyen situaciones en las que no se ha prestado consentimiento, aunque éste es sólo una implicación del observador, lo cual puede ser en ocasiones arbitrario. Por ello, los distingue de otro tipo de acciones u omisiones que constituyen "signos de consentimiento". Estos incluyen casos en los que, dado un contexto y determinadas convenciones, es el actor quien consiente, pero lo hace indirectamente: omitiendo hacer algo o absteniéndose de cumplir un deber sumido. La voluntad no la construye el observador a partir de una situación hipotética o de presunciones respecto de la racionalidad del emisor, sino que existe una abstención o un gesto que es un signo de la real voluntad del agente.

Para entender mejor la diferencia piénsese en el caso de quien cree que todo agente racional debiera manifestarse respecto de la autoridad justa, y que se auto percibe como alguien racional: ¿̇puede su silencio ser un signo de consentimiento cuando su Estado es justo? La atribución de voluntad es problemática porque en realidad nadie le ha preguntado a esa persona si avala o desea modificar las instituciones que lo rigen; en todo caso, será razonable que se niegue a obedecer eventualmente. Ahora imagínese que esta persona sí es consultada sobre su aprobación respecto de las instituciones, además cuenta con un mecanismo y espacio para exteriorizar su opinión, y también puede prever que sus conciudadanos tomarán una decisión colectiva, aun cuando guarde silencio o no esté presente en el momento de la votación. Este segundo escenario es diferente, ya que existe una pregunta directa previa que hace presumir el significado de la abstención de la persona, la cual no compromete seriamente su libertad individual. Tanto los observadores como quien es consultado sobre una determinada propuesta pueden prever la necesidad de tomar decisiones colectivas, la eventualidad de que dichas decisiones les afectarán, y pueden reconocer la existencia de oportunidades para discutir y reformular el esquema de 


\author{
Adriana L. Vercellone \\ Legitimidad política y voluntarismo: dos argumentos en favor del consentimiento tácito y la \\ 236 \\ democracia
}

normas en cuestión sin costo alguno. Por lo tanto, si lo desearan, intentarían modificar el contenido que sus gestos denotan, expresando directamente su descontento, u omitirían ser respaldados por las normas en sus actividades diarias. En resumen, bajo estas condiciones, los gestos u omisiones son signos que revelan la voluntad.

\title{
a.2. Contradicciones en la voluntad
}

Una última preocupación suscita la equivocación de presumir una intención opuesta a la real voluntad del agente. Más concretamente, la problemática aparece cuando sendas manifestaciones, expresas y tácitas, de voluntad se contradicen: es el caso de quien tácitamente aparenta una intención, pero manifiesta expresamente lo contrario. Imagínese que alguien grita abiertamente no estar de acuerdo con el régimen de propiedad privada del Estado mientras compra bienes en una subasta pública organizada y protegida por reglas estatales; o que organiza protestas en contra del gobierno mientras se aprovecha de la protección que la institución le brinda.

¿Existen razones para priorizar uno de esos gestos por encima del otro? Asumir que la voluntad real es la que se manifiesta de forma expresa, supone reconocerle mayor fuerza que a la evidenciada mediante signos indirectos. Lo contrario, implicaría la contradicción de atribuir un sentido a la voluntad de alguien, cuando abiertamente manifiesta lo contrario.

Los argumentos de Simmons revelan que tanto el signo verbal como el gesticular pueden ser igualmente prueba de la intención; y, por ello, no hay razones para priorizar una por sobre la otra. Así, cuando existen contradicciones las conclusiones son dos. Primero, que no puede afirmarse a priori que las expresiones manifiestas de voluntad de alguien sean prueba concluyente de sus deseos, más aún cuando existe un gesto en sentido contrario. Y, segundo, si las manifestaciones tácitas y expresas de voluntad no coinciden, deberá evaluarse la medida en que se satisfacen las condiciones que habilitan atribuir sentido a los signos o abstenciones y, así, cuán razonable es priorizar una o la otra.

\section{b. Modelo de la asociación voluntaria de Joseph Tussman}

Bajo ciertas condiciones, el consentimiento tácito es visto como una teoría que justifica la imposición coactiva de decisiones a las personas. Esto es así, por ejemplo, cuando las decisiones se adoptan por mayoría, cuando el 
voto es obligatorio o cuando el esquema institucional exige la predisposición a consentir. Esto es lo que se acusa a Kant, cuyo voluntarismo obliga a los ciudadanos a salir del estado de naturaleza y consentir, pero no explica por qué es bueno abandonar dicho estado o por qué alguien no podría apartarse de la sociedad. En estas condiciones, el consentimiento individual no es enteramente voluntario (Simmons, 1999).

Esta crítica toma mayor fuerza al considerar que la existencia y pertenencia a un Estado es ya ineludible. Las personas nacen en un contexto político preexistente y no elegido. Es imposible reconocer un momento inicial de asociación a ella, cuyo germen se halla sólo en el nacimiento, el cual determina de forma casi arbitraria las obligaciones políticas. Y siendo costoso o difícil salirse de una comunidad, la única alternativa viable para las personas suele ser participar activamente de la discusión política, intentando influir en el sistema que rige e influye en la vida diaria. Para algunos como Hirschman (citado por: Johnson, 1975), esto revela que no sólo la comunidad política apresa a sus miembros sino que también son involuntarios sus mecanismos de decisión.

Como respuesta, Tussman (1974) entiende que una mejor interpretación del consentimiento tácito requiere explorar, no sólo la idea de voluntad, sino también la naturaleza del concepto de membresía en una comunidad política. ${ }^{10}$ Contrariamente a quienes asumen la pertenencia a ella como algo impuesto y azaroso, Tussman sostiene que una agrupación es esencialmente voluntaria, ya que sin consenso el cuerpo político se disgregaría. Por ello, no sólo la justificación de la coacción y las instituciones se encuentra en el consentimiento, sino también la base de la comunidad toda.

$\mathrm{Su}$ argumento tiene dos partes. La primera, revela a la comunidad política como un colectivo voluntario. En ese sentido, Tusmann cree que cualquier agrupación es consecuencia de múltiples acuerdos celebrados entre sus miembros históricamente. Estos acuerdos pueden inclusive retrotraerse en el tiempo a personas diferentes de las que hoy lo constituyen. Pero siempre que alguien forma parte de un grupo, también pasa a formar parte del conjunto de reglas que lo rigen; es decir, asume como propias las normas y conductas que le dan sentido.

En ese sentido, no puede discutirse que el consentimiento y un sistema de acuerdos se halla en la base de una comunidad; y así, que la voluntad colectiva es el origen de sus reglas e instituciones. En concordancia, cualquier norma, como: "prohibido fumar" o "prohibido arrojar basura", aun cuando no es el resultado de una expresión directa de la propia voluntad, puede ser leída como "hemos acordado no fumar aquí" o "hemos acordado no arrojar basura”. En ese sentido, afirma:

10 En este punto, Tussman delinea un argumento cercano -aunque claramente diferente- a la teoría asociativa sobre la legitimidad. Las teorías asociativas encuentran múltiples defensores en la teoría contemporánea, por ejemplo, en Dworkin (1986), entre otros. 


\begin{abstract}
Adriana L. Vercellone
Legitimidad política y voluntarismo: dos argumentos en favor del consentimiento tácito y la

democracia
\end{abstract}

Una comunidad política es un grupo de personas vinculadas por un sistema de acuerdos; ser miembro de un cuerpo político implica formar parte de un sistema de acuerdos (...) Un grupo voluntario está compuesto por un número de individuos que, persiguiendo un objetivo común, acuerdan actuar en conjunto, poniéndose bajo una disciplina común, autoridad y obligación. La dificultad no se encuentra en entender qué es un grupo voluntario, sino en ver a cualquier comunidad política esencialmente como un grupo de tal carácter (Tussman, 1974: 3).

La segunda parte del argumento demuestra que la pertenencia a la comunidad también es voluntaria. La razón es que, frente a un descontento, abandonar la comunidad política no es la única opción que tienen habilitada los ciudadanos; en su lugar, pueden optar por revisar o modificar libremente las normas de convivencia y el sistema de acuerdos sobre el que se asienta la comunidad. Para Tusmann, esto constituye un modo razonable de escapar de la comunidad política indeseada.

Como la comunidad es el resultado de las variadas relaciones y acuerdos consensuados entre sus miembros, no es necesario un acto inicial de asociación a la comunidad (como si lo es en otras agrupaciones voluntarias, un club de barrio o un partido político). La posibilidad real de influir sobre el diseño de sus normas e instituciones equivale a poder elegir el tipo de comunidad en la que se desea vivir. Teniendo reconocida la posibilidad de celebrar nuevos acuerdos con los demás miembros del grupo, y hallándose en igualdad de condiciones y con plenas oportunidades para hacerlo, puede decirse que la pertenencia a la comunidad es voluntaria.

Justamente, el eje de la legitimación se halla en el modo en que las personas interactúan con las instituciones. Por ello, el voluntario ejercicio y participación dentro de sus mecanismos de discusión -o en su caso, optar por permanecer pasivo o guardar silencio-, es el modo en que se interactúa con los demás y el Estado. En otras palabras, el rol que asumen las personas en una comunidad y los deberes que tienen a cargo, no son impuestos.

Tussman no duda en reconocer que esto implica tratar a quienes no asumen sus tareas cívicas como "niños". Del mismo modo que un infante no puede siempre decidir, a quien no asume sus responsabilidades cívicas las decisiones colectivas le son atribuidas justificadamente (Pitkin, 1966; Tussman, 1974). Porque para Tusmman vivir en comunidad es una práctica voluntaria que se renueva en cada acción diaria. La cohabitación de personas en un territorio implica la mutua y permanente realización de transacciones con vecinos y familiares, para el intercambio de bienes o servicios y, con ello, la necesidad de acordar mínimos criterios de no interferencia, cooperación y coordinación. Quien diariamente participa de estos acuerdos, valiéndose de sus beneficios, debiera reconocer que indirectamente los avala.

Esta tesis aspira responder a la crítica de que una persona es miembro de una comunidad sólo si lo ha consentido directamente, pues no es necesaria la manifestación expresa y directa para formar parte de una comunidad. Y 
aunque el lugar de nacimiento es arbitrario, formar parte de una comunidad política puede ser visto como un acto voluntario porque, en definitiva, la comunidad misma tiene una justificación voluntaria.

\section{Democracia y consentimiento}

Los argumentos elaborados en torno al consentimiento tácito parecen sortear las críticas vinculadas con el voluntarismo y, en definitiva, responder a la cuestión sobre la legitimidad política en general. El voluntarismo entiende a la legitimidad como el entramado de obligaciones y deberes que surgen de las relaciones consensuadas entre personas y las instituciones que éstas conforman. Y así, los límites y potestades de la autoridad son el resultado de un cúmulo de permisiones y potestades voluntariamente asumidas por los ciudadanos. Las dos concepciones sobre el consentimiento tácito descritas ofrecen de algún modo sólidos argumentos para explicar la vinculación particular y voluntaria que los miembros de una comunidad política mantienen respecto de la autoridad, aun cuando ella no se manifieste de forma expresa y directa.

Sin embargo, la respuesta que ofrecen está sujeta a la satisfacción de importantes elementos del contexto que hacen posible manifestarse respecto de la autoridad. Porque no cualquier gesto manifiesta tácitamente la voluntad política, sino sólo aquellos que suceden bajo específicas circunstancias. Y así, el voluntarismo no legitima cualquier autoridad política, sino sólo aquella cuyas decisiones pueden ser influenciadas, modificadas y controladas por aquellos sobre quienes tiene efectos. Así, la plausibilidad de sus conclusiones está sujeta a la vigencia de dichas instancias y precondiciones de participación.

El vínculo entre democracia y consentimiento en este punto es indiscutible. Porque justamente la democracia apela al consentimiento como esencial mecanismo para la toma de decisiones, al exigir que sean los ciudadanos quienes les den contenido. Garantizando la libre participación de todos en igualdad de condiciones, las personas cuentan con oportunidades para manifestar sus preferencias respecto de las instituciones y principios para la comunidad. Y así, pone en marcha los mecanismos de adhesión voluntaria al orden político que las teorías del consentimiento exigen.

En otras palabras, el voluntarismo entiende que la autoridad política no es legítima por el mero hecho de ser tal, sino porque las personas asumen voluntariamente los compromisos y obligaciones que el ejercicio de la autoridad acarrea. En comunidades como las que hoy existen, ampliamente numerosas y plurales, solo es posible bajo la vigencia de formas de 

Adriana L. Vercellone
Legitimidad política y voluntarismo: dos argumentos en favor del consentimiento tácito y la 240 democracia

gobierno que tornen posible dichas manifestaciones de voluntad. Esto sucede fundamentalmente en democracia, cuyas normas son el resultado de mecanismos de discusión y participación abiertos e inclusivos, que garantizan el ejercicio pleno de libertades políticas.

La democracia se construye sobre un presupuesto fundamental: que el diálogo constituye la mejor vía para zanjar los desacuerdos; y su valor se halla en remarcar la importancia de la autonomía como fuente de obligaciones morales. En el ámbito individual, esto significa justificar solamente aquellas decisiones que son el resultado de las propias preferencias y elecciones. En una comunidad política, el autogobierno colectivo implica justificar las instituciones y decisiones que todos tienen oportunidad de influenciar y que pueden reconocer colectivamente como propias. De ese modo, los ciudadanos pueden saberse protagonistas del propio plan de vida y del sistema de normas que les rigen.

Bajo regímenes democráticos existen variadas vías formales e informales para formar parte de los procesos de decisión de la autoridad. En el mejor de los casos, estas vías son abiertas, públicas, y las personas participan en ellas disponiendo de completa y veraz información. Algunos toman partido de forma directa, votando, asistiendo a deliberaciones públicas, etc., hechos que denotan su expreso aval hacia las reglas de juego. Al comprometerse con los principios y reglas que guían el mecanismo de decisión, adhieren también a sus resultados.

Otros, permanecen pasivos ante dichas instancias. A pesar de ello, de algún modo también interactúan con el Estado y sus pares. Ya que la posibilidad de discutir cualquier política pública en un esquema institucional que satisface condiciones razonables para tomar decisiones colectivas, no pone en riesgo ningún valor humano relevante y garantiza el menor costo para quien desea disentir con sus conciudadanos. Votar, asistir a una sesión parlamentaria u organizar una propuesta para discutir una norma no implican un alto riesgo, por el contrario, son mínimos esfuerzos que se reivindican a quien tenga intenciones de decidir cómo convivir en comunidad.

De este modo, el diseño de instituciones democráticas nos acerca a escenarios casi ideales de legitimación de la autoridad, ya que condiciona que las abstenciones puedan ser interpretadas como un modo de comportarse respecto de los demás, y un gesto de adhesión a la autoridad y sus normas. Así: a) cualquier discusión sobre un asunto político que se lleve a cabo en una comunidad tiene implicancias para sus miembros si todos han tenido oportunidad de participar; b) la "oportunidad de participar" en un escenario democrático implica satisfacer las condiciones requeridas para que pueda construirse el consentimiento desde las abstenciones de las personas. 


\title{
a. ¿La democracia obliga a consentir?
}

\begin{abstract}
Alguien podría todavía objetar el esquema de decisión democrático, alegando que no es valioso o no lo prefiere como mecanismo para celebrar sus acuerdos. ¿Cómo puede ser voluntaria la pertenencia a una institución que exige la predisposición a consentir? Aceptarlo implica atribuir una decisión aún a quienes niegan la legitimidad del sistema democrático
\end{abstract} mismo.

Para entender cómo puede rechazarse este reclamo, hay que ver a la comunidad política como una agrupación voluntaria (Tussman, 1974). Esto supone que no hay un momento inicial de asociación a ella, y que su base es el acuerdo. Cualquier relación interpersonal a la que da lugar, se basa en acuerdos y promesas; y así el modo en que las personas se tratan o las relaciones que sostienen tiene efectos sobre lo que se deben mutuamente.

Esto significa reconocer a las personas como parte del entramado de acuerdos históricos que vincula a su comunidad. Toda vez que una persona forma parte de un grupo organizado de forma democrática puede identificar sus opciones y responsabilidades respecto de las normas e instituciones, las que le preceden, las actuales y las futuras. Quien pretende desvincularse de la autoridad, probablemente ya es parte de ella y de un acuerdo social, que puede sin costo intentar refundar y con amplias posibilidades para elegir como convivir con los demás, por ejemplo, discutiendo las decisiones, controlando su ejecución, etc. Inclusive, existe la posibilidad de discutir y modificar las mismas herramientas democráticas de decisión. Asumir esta tarea es inherente a la convivencia. Y quien lo rechaza, no es respetuoso de las libertades políticas ajenas ni de los acuerdos colectivos; en otras palabras, es alguien que desea vivir de manera aislada.

En definitiva, el modo apropiado de disentir con la autoridad y acusarla de ilegítima, requiere mostrar que no se la ha elegido o no se ha tenido oportunidad de elegir libremente las decisiones que ésta le imputa. Para lo cual es necesario considerar el contexto de decisión del agente, los antecedentes que preceden a una disposición, o su actual contexto de ejecución. De modo que, sin suficiente debate, procedimientos poco inclusivos o información incompleta, entre otros factores, razonablemente puede alegarse tal cosa. Pero, en definitiva, es una respuesta que debe evaluarse en consideración de las instituciones democráticas concretas de la comunidad en cuestión. 
Adriana L. Vercellone

Legitimidad política y voluntarismo: dos argumentos en favor del consentimiento tácito y la

\section{b. ¿Cualquier modelo de democracia?}

La precisión de las condiciones que Simmons describe acerca del consentimiento tácito, redunda en una última pregunta de interés: ¿cualquier forma democrática legitima la autoridad? Reconocemos variados modelos teóricos que han argumentado sobre la democracia, poniendo énfasis en sus diversos elementos: la participación, la igualdad, la libertad, la competencia, la representatividad, etc. En los últimos 40 años, este debate es especialmente enriquecedor y ha desarrollado como protagonistas a variadas teorías democráticas, como: la pluralista, la elitista, la competitiva y la deliberativa.

Estos modelos de democracia guardan importantes diferencias entre sí, ya que no todos plasman del mismo modo en la práctica los valores básicos democráticos. Para algunos, el mero reconocimiento de libertades políticas fundamentales (como la libertad de expresión, de asociación o de participación) no es suficiente para señalar a un gobierno como democrático, en especial cuando un número importante de ciudadanos no tiene sus necesidades básicas satisfechas -en cuyo caso, la oportunidad para hacer efectiva sus libertades se ve claramente muy limitada-. Para otros, dicho reconocimiento formal de libertades es suficiente, pues la democracia no es más que una regla de decisión que posibilita tomar decisiones (buenas o malas) acerca del reparto de recursos y la justicia.

Por ello, es difícil y discutible concluir que cualquier modelo de democracia satisfaga las condicionantes descritas por el voluntarismo. Dicho análisis requeriría profundizar un poco más en los modelos de democracia vigentes, la práctica de sus diseños institucionales, sus resultados reales, etc. Pero una valiosa reflexión de Carlos Nino sobre la democracia deliberativa permite sortear el tema.

Frente a la discusión sobre legitimidad y la imposibilidad de muchas comunidades de satisfacer las exigencias democráticas en todos sus espacios y niveles, Nino entiende que debe verse a dicha forma de gobierno como un ideal regulativo (Nino, citado por Martí, 2006); es decir, como un conjunto de estándares morales y políticos que debiera guiar las instituciones y toma de decisiones de una comunidad. Así, una comunidad será más democrática mientras más se acerque al ideal establecido.

De manera que es aceptable que algunas personas puedan justificada desvincularse de la autoridad cuando una democracia no es enteramente saludable, así como es natural que se suscite la discusión sobre su legitimidad de forma generalizada. De todos modos, esto no debilita el argumento voluntarista; al contrario, revela la importancia de la voluntad para la legitimidad política y la necesidad de discutir en profundidad la fuente y 
límites de las obligaciones políticas, reforzando las prácticas democráticas de una comunidad atendiendo a su contexto particular.

\section{Conclusiones}

Sostener que una institución es legítima implica justificar sus potestades y derechos, lo cual para el voluntarismo sólo es posible a partir de lo que las personas manifiestan sobre ella. Son los ciudadanos quienes forman y dan contenido a la autoridad y, por ello, la misma no puede ser legítima sino a partir de las relaciones voluntarias e intencionales que mantienen las personas en una comunidad política. Esta respuesta voluntarista es una de las más destacadas que reconoce la teoría política, dado su énfasis en la autonomía como fuente de obligaciones y la autoridad.

Sin embargo, no está exenta de problemas. Algunas de las objeciones señaladas a la versión clásica del voluntarismo político, pueden ser salvados apelando a una mejor reconstrucción de la noción de consentimiento, que dé cuenta de su valor y efectos. En esa línea de pensamiento, reconocemos dos teorías contemporáneas sobre el consentimiento tácito que ofrecen sólidos argumentos para reconocer a ciertos gestos individuales y omisiones la misma fuerza que a las expresiones directas de voluntad y, por lo tanto, fuerza suficiente para vincular a las personas a la autoridad. Por un lado, la teoría de Simmons especifica las condiciones bajo las cuales ciertos gestos y abstenciones pueden ser un signo de la voluntad. Por otro lado, Tussman reconoce a la comunidad y sus normas como el resultado de acuerdos e interacciones diarias que la personas no pueden dejar de reconocer como propias.

Estas manifestaciones tácitas sobre la voluntad dependen de importantes condicionantes que se vinculan con el contexto en que se toman las decisiones y se expresa la voluntad: reconocen plena libertad, conocimiento e intención en las acciones u omisiones de quienes se manifiestan respecto de la autoridad. En consecuencia, la teoría solo es plausible en determinados contextos de gobierno.

Que la plausibilidad y efectos del consentimiento político tenga que ver con el contexto de decisión, redunda en importantes apreciaciones sobre la democracia. En ese sentido, el voluntarismo y la democracia comparten un fundamento en común: la preocupación de la autonomía y la libertad como únicos antecedentes de las obligaciones morales y la comunidad política. En definitiva, si el voluntarismo es la mejor respuesta sobre legitimidad política, la democracia constituye la mejor forma de gobierno que permite legitimar a la comunidad y a sus formas de autoridad ante la ciudadanía. 


\footnotetext{
Adriana L. Vercellone

Legitimidad política y voluntarismo: dos argumentos en favor del consentimiento tácito y la

La pregunta acerca de cuál es la mejor propuesta sobre la democracia para llevar a la práctica, es una discusión abierta, interesante para futuras investigaciones. No obstante, de forma genérica puede concluirse que los modelos democráticos no son todos igualmente valiosos, pues algunos revelan en mejor medida los principios que toda democracia debiera suscribir. Y siendo la democracia un ideal regulativo, la autoridad gozará de mayor legitimidad y sus instituciones serán más abiertas, saludables e inclusivas, en la medida en que se preocupen más por respetan y desarrollar dichos principios.

\section{Referencias Bibliográficas}

DWORKIN, Ronald. 1986. Law's empire, Harvard University Press. Cambridge, EE. UU.

HUME, David. 1907. Essays: Moral, political, and literary (Vol. 1): Longmans, Green, and Company. London, England.

JOHNSON, Karen. 1975. "Political obligation and the voluntary association model of the state". Revista Ethics 86 (1), pp. 17-29.

LOCKE, John. 1969. Ensayo sobre el Gobierno Civil (Segundo Tratado sobre el Gobierno Civil). Aguilar. Madrid, España.

LOCKE, John. 2002. Segundo ensayo sobre el gobierno civil: un ensayo sobre el verdadero origen, alcance y finalidad del gobierno civil. Losada. Buenos Aires, Argentina.

MARTÍ, José Luis. 2006. La república deliberativa: una teoría de la democracia. Marcial Pons, Ediciones Jurídicas y Sociales. Madrid, España.

PETER, Fabienne. 2010. "Political legitimacy". Stanford Encyclopedia of Philosophy. Disponible en línea. En: https://stanford.library.sydney. edu.au/entries/legitimacy/. Fecha de consulta: 08/08/2018.

PITKIN, Hanna. 1965. "Obligation and Consent-I”. En: Revista The American Political Science Review, Nro. 59 (4), pp. 990-999.

PITKIN, Hanna. 1966. "Obligation and Consent-II" En: The American Political Science Review, No. 60 (1), pp. 39-52.

RAWLS, John. 1999. Justicia como equidad: materiales para una teoría de la justicia. Anaya, España. 
RAWLS, John. 2012. Teoría de la justicia. Fondo de cultura económica. México DF., México.

SELEME, Hugo Omar. 2010. "La legitimidad como autoría" En: Revista Brasilera de Filosofía $\mathrm{N}^{\circ}$ 234, pp. 73-99.

SIMMONS, A. John. 1976. “Tacit consent and political obligation” En: Revista Philosophy \& public affairs, p. 274-291.

SIMMONS, A. John. 1981. Moral principles and political obligations. Princeton University Press. New Jersey, EE. UU.

SIMMONS, A. John. 1999. “Justification and Legitimacy” En: Ethics, Nro. 109 (4), p. 739-771.

SIMMONS, A. John. 2009. “'Denisons' and'Aliens': Locke's Problem of Political Consent” En: Social theory and practice, Nro. 24 (2), pp. 161-182.

TUSSMAN, Joseph. 1974. Obligation and the body politic. Oxford University Press. Oxford, England.

VILAJOSANA RUBIO, Josep María. 2008. Identificación y justificación del derecho. Marcial Pons, Ediciones Jurídicas y Sociales. Barcelona, España.

WELLMAN, Christopher; SIMMONS John. 2005. Is there a duty to obey the law? Cambridge University Press. Cambridge, EE. UU. 

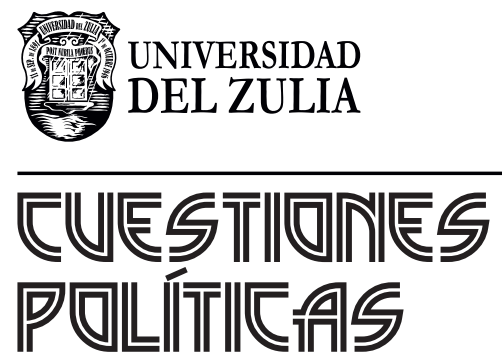

Vol. $37 \mathrm{~N}^{\circ} 64$

Esta revista fue editada en formato digital y publicada en junio de 2020, por el Fondo Editorial Serbiluz, Universidad del Zulia. Maracaibo-Venezuela 